\title{
Promoting Functional Activity Among Nursing Home Residents: A Cross-Sectional Study on Barriers Experienced by Nursing Staff
}

Citation for published version (APA):

Kuk, N. O., Zijlstra, G. A. R., Bours, G. J. J. W., Hamers, J. P. H., Tan, F. E. S., \& Kempen, G. I. J. M. (2018). Promoting Functional Activity Among Nursing Home Residents: A Cross-Sectional Study on Barriers Experienced by Nursing Staff. Journal of Aging and Health, 30(4), 605-623. https://doi.org/10.1177/0898264316687407

Document status and date:

Published: 01/04/2018

DOI:

10.1177/0898264316687407

Document Version:

Publisher's PDF, also known as Version of record

\section{Document license:}

Taverne

Please check the document version of this publication:

- A submitted manuscript is the version of the article upon submission and before peer-review. There can be important differences between the submitted version and the official published version of record.

People interested in the research are advised to contact the author for the final version of the publication, or visit the DOI to the publisher's website.

- The final author version and the galley proof are versions of the publication after peer review.

- The final published version features the final layout of the paper including the volume, issue and page numbers.

Link to publication

\footnotetext{
General rights rights.

- You may freely distribute the URL identifying the publication in the public portal. please follow below link for the End User Agreement:

www.umlib.nl/taverne-license

Take down policy

If you believe that this document breaches copyright please contact us at:

repository@maastrichtuniversity.nl

providing details and we will investigate your claim.
}

Copyright and moral rights for the publications made accessible in the public portal are retained by the authors and/or other copyright owners and it is a condition of accessing publications that users recognise and abide by the legal requirements associated with these

- Users may download and print one copy of any publication from the public portal for the purpose of private study or research.

- You may not further distribute the material or use it for any profit-making activity or commercial gain

If the publication is distributed under the terms of Article $25 \mathrm{fa}$ of the Dutch Copyright Act, indicated by the "Taverne" license above, 


\section{Promoting Functional} Activity Among Nursing Home Residents: A

\section{Cross-Sectional Study on Barriers Experienced by Nursing Staff}

Journal of Aging and Health 20I8, Vol. 30(4) 605-623

(C) The Author(s) 2017

Reprints and permissions: sagepub.com/journalsPermissions.nav DOI: $10.1177 / 0898264316687407$ journals.sagepub.com/home/jah

@SAGE

\author{
Nienke O. Kuk, MSc', G. A. Rixt Zijlstra, PhD', \\ Gerrie J. J. W. Bours, PhD, RN ${ }^{1,2}$, \\ Jan P. H. Hamers, PhD, RN', \\ Frans E. S. Tan, $\mathrm{PhD}^{3}$, \\ and Gertrudis I. J. M. Kempen, PhD'
}

\begin{abstract}
Objective: To obtain insight into (a) the prevalence of nursing staffexperienced barriers regarding the promotion of functional activity among nursing home residents, and (b) the association between these barriers and nursing staff-perceived promotion of functional activity. Method: Barriers experienced by 368 nurses from $4 \mathrm{I}$ nursing homes in the Netherlands were measured with the MAastrlcht Nurses Activity INventory (MAINtAIN)barriers; perceived promotion of functional activities was measured with the MAINtAIN-behaviors. Descriptive statistics and hierarchical linear regression analyses were performed. Results: Most often experienced barriers were
\end{abstract}

\footnotetext{
'Department of Health Services Research, CAPHRI Care and Public Health Research Institute, Maastricht University, The Netherlands

${ }^{2}$ Research Centre for Autonomy and Participation for Persons with a Chronic Illness, Zuyd University of Applied Sciences, Heerlen, The Netherlands

${ }^{3}$ Department of Methodology and Statistics, CAPHRI Care and Public Health Research Institute, Maastricht University, The Netherlands
}

\title{
Corresponding Author:
}

Nienke O. Kuk, Maastricht University, P.O. Box 616, 6200 MD Maastricht, The Netherlands. Email: n.kuk@maastrichtuniversity.nl 
staffing levels, capabilities of residents, and availability of resources. Barriers that were most strongly associated with the promotion of functional activity were communication within the team, (a lack of) referral to responsibilities, and care routines. Discussion: Barriers that are most often experienced among nursing staff are not necessarily the barriers that are most strongly associated with nursing staff-perceived promotion of functional activity.

\section{Keywords}

nursing homes, barriers, functional activity, nursing staff, activities of daily living

\section{Introduction}

Being functionally active is important for all people, including nursing home residents who are under supervision $24 \mathrm{hr}$ a day. In nursing home residents, being active and performing functional activities is associated with less disruptive behavior (Resnick, Galik, \& Boltz, 2013), less anxiety (Resnick et al., 2013), higher self-esteem (Blair, 1997), and a higher quality of life (Edvardsson, Petersson, Sjogren, Lindkvist, \& Sandman, 2014). Initiatives to maintain or improve functional activity among nursing homes residents have been proposed worldwide (Peri et al., 2008; Resnick et al., 2013; Slaughter et al., 2015). Nonetheless, several studies have shown that inactivity is common in nursing home residents (den Ouden et al., 2015; Harper Ice, 2002; MacRae, Schnelle, Simmons, \& Ouslander, 1996). A recent observation study in the Netherlands showed that nursing home residents, including mobile residents, were sitting or lying for about $90 \%$ of the observed moments during the day (den Ouden et al., 2015). To improve functional activity among nursing home residents, nursing staff can play an important role. They can encourage residents to be active and to act as independently as possible during daily care activities (Resnick et al., 2013), strengthen residents' selfefficacy (Sabol et al., 2011), for example, by probing residents to perform activities, or complimenting residents when they have performed certain activities. A recent study among nursing staff found that some functional activities, such as household activities (e.g., setting and clearing the table), are perceived to be less often promoted by the nursing staff than other functional activities, such as activities of daily living (ADLs; Kuk, Bours, Zijlstra, Hamers, \& Kempen, 2015). Evidence suggests that nursing staff may be inclined to take over the activities of nursing home residents (Brown, McWilliam, \& Ward-Griffin, 2006; Davies, Ellis, \& Laker, 2000; Resnick et al., 2009). Den Ouden and colleagues (den Ouden et al., 2016) showed that 
in $45 \%$ of the observations when nursing staff were involved in residents' activities, the staff performed the activity for the resident instead of allowing the residents to do the activity themselves. The observers in this study indicated that this behavior by the nursing staff was often unnecessary.

On a more general level, previous studies have shown that certain barriers may influence the behavior of nursing staff, for example, when adopting evidence-based practices or using guidelines (Grol \& Wensing, 2004; Jun, Kovner, \& Stimpfel, 2016; Solomons \& Spross, 2011). Less evidence is available on the barriers nursing staff experience with regard to promoting functional activity among older people. Previous studies showed that nursing staff may not encourage residents to perform functional activities because they think residents are not capable of performing them (Kuk, Zijlstra, Bours, Hamers, \& Kempen, 2016; Resnick et al., 2008) or nursing staff may think that family expects them to perform certain activities for residents (Galik, Resnick, \& Pretzer-Aboff, 2009; Kuk et al., 2016; Resnick et al., 2008). Other barriers that may prevent nursing staff from promoting functional activity are a high workload or a lack of social support (Kuk et al., 2016; Resnick et al., 2006). These barriers can act on different levels. They may be related to the residents (e.g., fear of falling), the nursing staff (e.g., lack of self-efficacy), the social context (e.g., lack of social support), or the organizational and economic context (e.g., lack of resources; Grol \& Wensing, 2004; Kuk et al., 2016). Although previous studies revealed some of the barriers nursing staff experience, they do not show how frequently these barriers are experienced and how these barriers are related with the promoting behavior of nursing staff. It is unknown whether the barriers that are most often experienced are also the barriers that are most strongly associated with the behavior of nursing staff. Insight into the prevalence and relative importance of the barriers is important to develop strategies to improve the promotion of functional activity by nursing staff.

The purpose of this study was to obtain an insight into the prevalence of the barriers that nursing staff experience regarding promoting functional activity among nursing home residents, and the association between these barriers and nursing staff-perceived behavior regarding the promotion of functional activity. In this study, a distinction is made between barriers related to the residents, the professionals, the social context, and the organizational and economic context.

\section{Material and Method}

\section{Design}

In January and February 2014, a nationwide cross-sectional study was conducted to collect data from nursing staff employed at nursing homes in the 
Netherlands. The Medical Ethical Review Committee of Maastricht University (14-5-002) approved the study.

\section{Setting, Participants, and Procedures}

In the Netherlands, nursing home care is provided in somatic and psychogeriatric wards. Residents with psychogeriatric problems, such as dementia, primarily live in psychogeriatric wards, while somatic wards provide care to residents with physical problems (Schols, Crebolder, \& van Weel, 2004). The large majority of the nursing staff in Dutch nursing homes are certified nurse assistants (CNAs), who have followed a secondary vocational training of 3 years. In addition, care is provided by registered nurses (RNs) with 4 years of vocational training and bachelor-educated RNs.

Nursing homes in the Netherlands were stratified according to five regions (north, east, south, west, and central). From each region, a random sample was drawn, proportionate to the total number of nursing homes in that region. In total, 100 nursing homes were invited to participate. To exclude care homes that have a single small nursing home ward but mainly provide care that is less intensive than regular nursing home care, the first author verified by telephone whether the nursing homes provided care to at least 25 somatic and/or 25 psychogeriatric residents. This led to the exclusion of 25 facilities; furthermore, one nursing home was excluded because it had closed its doors at the time of recruitment. Of the remaining 74 nursing homes, 46 agreed to participate.

Based on practical considerations, nursing homes with both psychogeriatric and somatic wards were invited to participate with $16 \mathrm{RNs}$ or CNAs, eight from each ward type. Nursing homes with only somatic or only psychogeriatric wards were asked to participate with a total of 10 RNs or CNAs. In this way, a total of $622 \mathrm{RNs}$ and CNAs could potentially participate. In addition to being an RN or CNA, participating nursing staff had to work at least $12 \mathrm{hr}$ per week, to ensure that they had enough insight into daily practice. Nursing staff working exclusively night shifts were excluded from participation because of the fairly limited opportunities to promote functional activities during this time of day. In each participating nursing home, a local contact person randomly administered a questionnaire among eligible nursing staff and returned the anonymously completed questionnaires within 2 weeks.

\section{Measures}

The barriers nursing staff experience regarding promoting functional activity were assessed with the MAastrIcht Nurses Activity INventory (MAINtAIN)barriers (Kuk et al., 2016). This inventory comprises 33 nine-point scaled 
items ranging from never to always, or completely disagree to completely agree. A distinction is made between the different levels barriers relate to, namely, (a) the residents, (b) the professionals, (c) the social context, and (d) the organizational and economic context. Data on the extent to which nursing staff perceive that they promote functional activities were collected with the MAINtAIN-behaviors (Kuk et al., 2016) inventory. In this article, the phrase "behavior of the nursing staff" is applied to indicate their perceived behavior regarding the promotion of functional activities. The 19-itemed MAINtAINbehaviors inventory comprises three subscales assessing the extent to which nursing staff promote independence during ADLs, such as bathing or dressing (eight items); household activities, such as setting and clearing the table or preparing a sandwich (six items); and miscellaneous activities, such as encouraging informal caregivers not to take over activities or encouraging residents to participate in organized activities (five items). Respondents rate the items on a nine-point scale ranging from never to always. The internal consistency for each of the three subscales ranged from .77 to .83 (Kuk et al., 2015). The MAINtAIN-barriers and MAINtAIN-behaviors are the two parts of the MAINtAIN inventory (available via open access; Kuk et al., 2016). A previous study showed MAINtAIN's usability and content validity (Kuk et al., 2016).

Background characteristics of the nursing staff (age, sex, profession [CNA or RN], the ward type the nursing staff worked in [psychogeriatric or somatic], number of work hours per week, and years of professional experience) were assessed using single-item questions.

\section{Data Analyses}

Means and proportions were used to describe the background characteristics. Regarding the MAINtAIN-barriers, the scores of the positively formulated items were reversed so that higher scores always indicate stronger experienced barriers. For each barrier, the mean score and standard deviation were calculated. In addition, to determine the proportion of respondents who experienced a barrier to a lower or higher extent, the answer options of the MAINtAIN-barrier items were categorized into three categories: low $($ score $=1-3)$, medium (score $=4-6)$, and high $($ score $=7-9)$. Missing values $(0 \%-2.2 \%)$ on the items of the MAINtAIN-barriers were not imputed (i.e., not replaced by other values). Regarding the MAINtAIN-behaviors, mean scores and standard deviations were calculated for the ADLs subscale, household activities subscale, and miscellaneous activities subscale. Missing values on the items of a subscale were imputed with the respondent's average score for the other items of that subscale, if at least $75 \%$ of the items of the 
subscale had been completed. Missing data for the ADLs, household, and miscellaneous subscales were imputed for a total of $4.9 \%, 2.4 \%$, and $1.9 \%$ of the respondents, respectively. After imputation, $0.8 \%$ remained missing for the ADL and miscellaneous activities subscales, and $0.5 \%$ for the household activities subscale, due to respondents who did not complete at least $75 \%$ of the items. Given the few remaining missing values on the MAINtAINbarriers and MAINtAIN-behaviors, these missing values were not imputed as they are unlikely to impact the outcomes.

To determine the association between each nine-point-scaled barrier and each subscale of the MAINtAIN-behaviors, hierarchical linear regression analyses (random intercept; Level 1, nursing staff; Level 2, nursing home) were performed. In each analysis, one barrier and one subscale of the MAINtAIN-behaviors were used. The variables ward type and profession were added to each analysis to control for potential confounding. For each model, unstandardized $B$ coefficients $(B \mathrm{~s})$, standard errors, $p$ values, and intra-class coefficients (ICCs) were determined. To account for multiple comparisons, a Bonferroni-Holm correction was used, with the global significance level of .05. Sensitivity analyses were conducted by imputing the missing scores on the MAINtAIN-behaviors subscales (for respondents who completed at least $75 \%$ of the items on that scale) with either one or nine and comparing the results of these analyses. To rank the barriers according to the strength of the associations, the mean strength of the association between each barrier and the three functional activity subscales was determined (the mean of the three $B \mathrm{~s}$ ). Mean scores for each barrier were used to rank them; barriers were also ranked based on the $B$ s following the adjusted hierarchical linear regressions analyses. In addition, simple and hierarchical linear regression analyses were conducted without the potential confounders to determine the $B$ coefficients and allow comparison of the ranked mean of the three $B \mathrm{~s}$ with the ranked barriers' mean scores. All statistical analyses were performed using SPSS Statistics (version 22, IBM, Armonk, New York, USA).

\section{Results}

\section{Sample Characteristics}

Of the 448 respondents from 42 nursing homes (response rate $=72 \%$, range $=50 \%-100 \%$ per nursing home) who completed the MAINtAIN, 80 were excluded because they did not meet the inclusion criteria (i.e., working exclusively night shifts $[n=18]$, not working in a somatic or psychogeriatric ward $[n=35]$, not certified as an RN or CNA [ $n=24]$, or a combination of these reasons $[n=3])$. The 368 eligible respondents represented 41 nursing homes. 
Table I. Sample Characteristics $(N=368) .{ }^{a}$

\begin{tabular}{lcc}
\hline & $n(\%)$ & $M \pm S D$ \\
\hline Gender & $346(95)$ & \\
$\quad$ Female & $20(5)$ & \\
Male & & \\
Ward type & $231(63)$ & \\
$\quad$ Psychogeriatric ward & $137(37)$ & \\
$\quad$ Somatic ward & & \\
Profession & $275(75)$ & $17.3 \pm 10.6$ \\
CNA & $93(25)$ & $28.7 \pm 5.4$ \\
$\quad$ RN & & 11.6 \\
Age (years) & & \\
Professional experience (years) & & \\
Work hours per week & & \\
\hline
\end{tabular}

Note. $\mathrm{CNA}=$ certified nurse assistant; $\mathrm{RN}=$ registered nurse (vocationally trained or bachelor educated).

aN does not always add up to 368 due to missing data.

The mean age of the included respondents was 41.8 years $(S D=11.6$ years), and $231(63 \%)$ of them worked in a psychogeriatric ward. Other sample characteristics are displayed in Table 1.

The extent to which the nursing staff promoted functional activities varied; the mean scores for the ADLs, household activities, and miscellaneous activities were $6.9(S D=1.2), 4.1(S D=1.9)$, and $6.7(S D=1.5)$, respectively, out of a theoretical range from 1 to 9 (data not tabulated).

\section{Prevalence of Nursing Staff-Experienced Barriers}

Table 2 provides an overview of the barriers nursing staff experienced with regard to promoting functional activity, arranged according to the level to which they relate: the residents, the professionals, the social context, or the organizational and economic context. As the table shows, the mean scores on the barriers ranged from 2.39 (item on sense of importance on the professional level) to 5.47 (item on staffing level on the organizational and economic context level), out of a theoretical range from 1 to 9 . Generally, barriers related to the organizational and economic context were rated most often as a barrier, with the top three ranging from a mean score of 5.47 ( $S D=2.48,39 \%$ "high") for staffing level to 5.02 ( $S D=2.46,33 \%$ "high") for time. Prevalent experienced barriers within the other three levels were the capabilities of the residents $(M=5.37, S D=2.52,39 \%$ "high"), conflict: time consuming 
Table 2. Mean Scores, Standard Deviations, and Prevalence of Nursing StaffExperienced Barriers for Promoting Functional Activities $(N=368)$.

\begin{tabular}{|c|c|c|c|c|}
\hline Barriers & $M \pm S D$ & Low $^{\mathrm{a}}(\%)$ & Medium $^{\mathrm{a}}(\%)$ & $\mathrm{High}^{\mathrm{a}}(\%)$ \\
\hline \multicolumn{5}{|l|}{ Residents } \\
\hline Capabilities residents & $5.37 \pm 2.52$ & 29 & 32 & 39 \\
\hline Residents' fear & $4.61 \pm 1.22$ & 19 & 76 & 5 \\
\hline Attitude residents & $4.54 \pm 1.74$ & 28 & 58 & 13 \\
\hline Attention-seeking behavior & $4.37 \pm 1.88$ & 34 & 54 & 12 \\
\hline $\begin{array}{l}\text { Residents' and families' expectations } \\
\text { regarding care }\end{array}$ & $4.34 \pm 2.02$ & 36 & 49 & 15 \\
\hline Learned dependency & $4.25 \pm 2.10$ & 42 & 41 & 17 \\
\hline Relevance for residents & $3.32 \pm 2.55$ & 64 & 19 & 17 \\
\hline Visibility of results & $2.73 \pm 2.00$ & 76 & 17 & 7 \\
\hline \multicolumn{5}{|l|}{ Professionals } \\
\hline Conflict: time consuming & $5.10 \pm 2.45$ & 28 & 40 & 31 \\
\hline Self-efficacy & $3.33 \pm 2.37$ & 63 & 24 & 13 \\
\hline Prioritizing time over care & $3.31 \pm 2.09$ & 62 & 26 & 12 \\
\hline Availability of expertise & $3.10 \pm 1.92$ & 70 & 21 & 9 \\
\hline Sense of difficulty & $2.57 \pm 1.91$ & 79 & 16 & 5 \\
\hline Task perception: taking responsibility & $2.54 \pm 1.72$ & 79 & 17 & 4 \\
\hline Outcome expectations & $2.50 \pm 2.07$ & 78 & 14 & 8 \\
\hline $\begin{array}{l}\text { Task perception: task of } \\
\text { physiotherapist }\end{array}$ & $2.49 \pm 1.89$ & 79 & 17 & 5 \\
\hline Risks for residents & $2.45 \pm 1.61$ & 79 & 19 & 2 \\
\hline Sense of importance & $2.39 \pm 1.63$ & 81 & 16 & 4 \\
\hline \multicolumn{5}{|l|}{ Social context } \\
\hline Expectations of colleagues & $4.69 \pm 2.61$ & 42 & 29 & 29 \\
\hline Care routines & $4.36 \pm 2.22$ & 39 & 38 & 22 \\
\hline Communication within team & $3.58 \pm 2.05$ & 58 & 31 & 11 \\
\hline Support of manager & $3.20 \pm 2.21$ & 66 & 24 & 10 \\
\hline Social support of colleagues & $3.18 \pm 2.04$ & 69 & 20 & 11 \\
\hline Referral to responsibility & $3.10 \pm 1.76$ & 65 & 31 & 4 \\
\hline Collaboration with experts & $2.94 \pm 2.35$ & 70 & 17 & 13 \\
\hline \multicolumn{5}{|l|}{ Organizational and economic context } \\
\hline Staffing level & $5.47 \pm 2.48$ & 26 & 34 & 39 \\
\hline Availability of resources & $5.12 \pm 2.16$ & 24 & 48 & 28 \\
\hline Time & $5.02 \pm 2.46$ & 35 & 32 & 33 \\
\hline Educational opportunities & $4.99 \pm 2.55$ & 33 & 33 & 34 \\
\hline Organizational readiness & $4.93 \pm 2.84$ & 37 & 27 & 36 \\
\hline Priority within organization & $4.47 \pm 2.25$ & 37 & 41 & 22 \\
\hline Rules and regulations & $4.17 \pm 2.35$ & 45 & 36 & 19 \\
\hline Presence of experts & $3.31 \pm 2.08$ & 65 & 24 & 11 \\
\hline
\end{tabular}

Note. Barriers presented per level and ranked within that level based on mean scores. A higher mean score indicates a stronger experienced barrier.

aBarriers scored on the nine-point scales were categorized into low (score = I-3), medium (score $=4-6$ ), and high $($ score $=7-9)$. Percentages may not add up to $100 \%$ because of rounding. 
( $M=5.10, S D=2.45,31 \%$ "high"), and the expectations of colleagues ( $M=4.69, S D=2.61,29 \%$ "high"). The three lowest rated barriers were related to the level of the professionals, with sense of importance having the lowest mean score of all barriers ( $M=2.39, S D=1.63,4 \%$ "high").

\section{Associations Between Experienced Barriers and Promotion of Functional Activity}

The associations between the extent to which barriers were experienced and the extent to which nursing staff promoted ADLs, household activities, and miscellaneous activities are presented in Table 3. For most barriers, a stronger experience of a barrier is associated with less promotion of ADLs, household activities, and miscellaneous activities. For example, less social support from colleagues is associated with less promotion of all the kinds of activities. There are some exceptions, in particular for the barriers related to the residents; none of these barriers are significantly associated with the promotion of all three kinds of activities.

The strength of the associations varies per barrier. While the barriers related to the residents are not, or weakly, associated with the extent to which ADLs, household activities, and miscellaneous activities are promoted, most barriers related to professionals and to the organizational and economic context are moderately associated. Compared with the barriers related to the residents, professionals, and the organizational and economic context, some barriers related to the social context are slightly more strongly associated with the three outcome measures, in particular (a lack of) communication within the team about the promotion of activities $(B=-0.34$ to $-0.36, p<$ $.001)$ and (a lack of) referring colleagues to their responsibility in not taking over activities $(B=-0.28$ to $-0.30, p<.001)$. The sensitivity analyses, in which missing data on the functional activity subscales were imputed with either 1 or 9, showed similar results (data not shown; available upon request).

\section{Relative Importance of the Experienced Barriers}

Table 4 provides an overview of the relative importance of the barriers, based upon (a) how often they are experienced (i.e., the mean score on the ninepoint scale) and (b) the mean strength of the association between a barrier and the promotion of ADLs, household activities, and miscellaneous activities (data on mean strength of associations can be derived from the $B$ s in Table 3 ). The most often experienced barriers are staffing levels, capabilities of residents, and availability of resources. In contrast, the barriers that are most strongly associated with the behavior of nursing staff are communication 
Table 3. Associations Between Nursing Staff-Experienced Barriers and the Promotion of ADLs, Household Activities, and Miscellaneous Activities.

\begin{tabular}{|c|c|c|c|c|c|c|c|c|c|}
\hline & \multicolumn{3}{|c|}{$\begin{array}{c}\mathrm{ADL} \\
\text { subscale }\end{array}$} & \multicolumn{3}{|c|}{$\begin{array}{l}\text { Household activities } \\
\text { subscale }\end{array}$} & \multicolumn{3}{|c|}{$\begin{array}{l}\text { Miscellaneous } \\
\text { activities subscale }\end{array}$} \\
\hline & B & SE & $p$ & B & $S E$ & $p$ & B & SE & $p$ \\
\hline \multicolumn{10}{|l|}{ Barriers related to resident } \\
\hline Learned dependency & $-0.10^{*}$ & -0.03 & .001 & $-0.18 *$ & -0.04 & $<.001$ & -0.04 & -0.04 & .228 \\
\hline Visibility of results & $-0.09 *$ & -0.03 & .005 & -0.06 & -0.04 & .152 & -0.09 & -0.04 & .021 \\
\hline Attitude residents & -0.07 & -0.04 & .042 & $-0.16 *$ & -0.05 & .001 & -0.01 & -0.04 & .762 \\
\hline $\begin{array}{l}\text { Residents' and families' } \\
\text { expectations regarding } \\
\text { care }\end{array}$ & -0.07 & -0.03 & .021 & -0.07 & -0.04 & .099 & -0.02 & -0.04 & .593 \\
\hline Capabilities residents & $0.09 *$ & -0.03 & .001 & 0.00 & -0.03 & .996 & 0.07 & -0.03 & .021 \\
\hline Relevance for residents & -0.01 & -0.02 & .761 & -0.04 & -0.03 & .193 & -0.03 & -0.03 & .384 \\
\hline Residents' fear & -0.02 & -0.05 & .743 & -0.05 & -0.07 & .430 & 0.10 & -0.06 & .095 \\
\hline $\begin{array}{l}\text { Attention-seeking } \\
\text { behavior }\end{array}$ & -0.03 & -0.03 & .323 & -0.01 & -0.04 & .759 & 0.02 & -0.04 & .643 \\
\hline \multicolumn{10}{|c|}{ Barriers related to the professionals } \\
\hline $\begin{array}{l}\text { Task perception: taking } \\
\text { responsibility }\end{array}$ & $-0.25^{*}$ & -0.03 & $<.001$ & $-0.14 *$ & -0.05 & .003 & $-0.28 *$ & -0.04 & $<.001$ \\
\hline Sense of importance & $-0.27^{*}$ & -0.04 & $<.001$ & $-0.15 *$ & -0.05 & .002 & $-0.23 *$ & -0.05 & $<.001$ \\
\hline Availability of expertise & $-0.23^{*}$ & -0.03 & $<.001$ & $-0.16 *$ & -0.04 & $<.001$ & $-0.17^{*}$ & -0.04 & $<.001$ \\
\hline $\begin{array}{l}\text { Prioritizing time over } \\
\text { care }\end{array}$ & $-0.16 *$ & -0.03 & $<.001$ & $-0.16 *$ & -0.04 & $<.001$ & $-0.12^{*}$ & -0.04 & .001 \\
\hline $\begin{array}{l}\text { Conflict: time } \\
\text { consuming }\end{array}$ & $-0.08^{*}$ & -0.03 & .002 & $-0.17 *$ & -0.03 & $<.001$ & -0.08 & -0.03 & .008 \\
\hline Sense of difficulty & $-0.11 *$ & -0.03 & .001 & -0.02 & -0.04 & .631 & $-0.16 *$ & -0.04 & $<.001$ \\
\hline Risks for residents & -0.08 & -0.04 & .042 & -0.02 & -0.05 & .694 & -0.05 & -0.05 & .268 \\
\hline Outcome expectations & -0.02 & -0.03 & .460 & -0.04 & -0.04 & .292 & -0.05 & -0.04 & .138 \\
\hline Self-efficacy & 0.02 & -0.03 & .361 & 0.02 & -0.03 & .656 & 0.01 & -0.03 & .824 \\
\hline $\begin{array}{l}\text { Task perception: task of } \\
\text { physiotherapist }\end{array}$ & -0.03 & -0.03 & .354 & 0.01 & -0.04 & .813 & -0.02 & -0.04 & .694 \\
\hline \multicolumn{10}{|c|}{ Barriers related to the social context } \\
\hline $\begin{array}{l}\text { Communication within } \\
\text { team }\end{array}$ & $-0.35 *$ & -0.02 & $<.001$ & $-0.34^{*}$ & -0.04 & $<.001$ & $-0.36^{*}$ & -0.03 & $<.001$ \\
\hline $\begin{array}{l}\text { Referral to } \\
\text { responsibility }\end{array}$ & $-0.29 *$ & -0.03 & $<.001$ & $-0.28 *$ & -0.04 & $<.001$ & $-0.30 *$ & -0.04 & $<.001$ \\
\hline Care routines & $-0.24^{*}$ & -0.03 & $<.001$ & $-0.27^{*}$ & -0.03 & $<.001$ & $-0.23^{*}$ & -0.03 & $<.001$ \\
\hline $\begin{array}{l}\text { Social support of } \\
\text { colleagues }\end{array}$ & $-0.27^{*}$ & -0.03 & $<.001$ & $-0.22^{*}$ & -0.04 & $<.001$ & $-0.20 *$ & -0.04 & $<.001$ \\
\hline Support of manager & $-0.20 *$ & -0.03 & $<.001$ & $-0.19 *$ & -0.04 & $<.001$ & $-0.22 *$ & -0.03 & $<.001$ \\
\hline $\begin{array}{l}\text { Expectations of } \\
\text { colleagues }\end{array}$ & $-0.16 *$ & -0.02 & $<.001$ & $-0.24 *$ & -0.03 & $<.001$ & $-0.20 *$ & -0.03 & $<.001$ \\
\hline $\begin{array}{l}\text { Collaboration with } \\
\text { experts }\end{array}$ & $-0.09 *$ & -0.03 & .001 & -0.06 & -0.03 & .096 & -0.08 & -0.03 & .008 \\
\hline
\end{tabular}


Table 3. (continued)

\begin{tabular}{|c|c|c|c|c|c|c|c|c|c|}
\hline & \multicolumn{3}{|c|}{$\begin{array}{c}\mathrm{ADL} \\
\text { subscale }\end{array}$} & \multicolumn{3}{|c|}{$\begin{array}{l}\text { Household activities } \\
\text { subscale }\end{array}$} & \multicolumn{3}{|c|}{$\begin{array}{l}\text { Miscellaneous } \\
\text { activities subscale }\end{array}$} \\
\hline & B & SE & $p$ & B & SE & $p$ & B & SE & $p$ \\
\hline \multicolumn{10}{|c|}{ Barriers related to organizational and economic context } \\
\hline $\begin{array}{l}\text { Priority within } \\
\text { organization }\end{array}$ & $-0.22^{*}$ & -0.03 & $<.001$ & $-0.20 *$ & -0.04 & $<.001$ & $-0.25^{*}$ & -0.03 & $<.001$ \\
\hline Presence of experts & $-0.20^{*}$ & -0.03 & $<.001$ & $-0.18^{*}$ & -0.04 & $<.001$ & $-0.23 *$ & -0.03 & $<.001$ \\
\hline Availability of resources & $-0.14^{*}$ & -0.03 & $<.001$ & $-0.15^{*}$ & -0.04 & $<.001$ & $-0.17 *$ & -0.03 & $<.001$ \\
\hline $\begin{array}{l}\text { Educational } \\
\text { opportunities }\end{array}$ & $-0.12^{*}$ & -0.02 & $<.001$ & $-0.16 *$ & -0.03 & $<.001$ & $-0.17^{*}$ & -0.03 & $<.001$ \\
\hline Time & $-0.13^{*}$ & -0.03 & $<.001$ & $-0.18^{*}$ & -0.03 & $<.001$ & $-0.13^{*}$ & -0.03 & $<.001$ \\
\hline Rules and regulations & $-0.14^{*}$ & -0.03 & $<.001$ & $-0.15^{*}$ & -0.03 & $<.001$ & $-0.14 *$ & -0.03 & $<.001$ \\
\hline $\begin{array}{l}\text { Organizational } \\
\text { readiness }\end{array}$ & $-0.07 *$ & -0.02 & .003 & $-0.19 *$ & -0.03 & $<.001$ & -0.07 & -0.03 & .013 \\
\hline Staffing level & $-0.07 *$ & -0.03 & .004 & $-0.13^{*}$ & -0.03 & $<.001$ & -0.05 & -0.03 & .079 \\
\hline
\end{tabular}

Note. Associations between each of the 33 barriers (scale = 1-9) and each subscale of the MAINtAINbehaviors (scale = I-9) were determined using hierarchical linear regression analyses (random intercept; Level I, nursing staff; Level 2, nursing home), including the factors ward type and profession. In each analysis, one barrier and one subscale of the MAINtAIN-behaviors were used. Answer options for positively formulated factors were reversed in these analyses. Within each level, barriers are ranked according to the mean strength of the associations. Due to missing data, sample size for each analysis varies from 356 to 366 . ICCs range from .01 to .08 , .II to .18 , and .00 to .04 , for the analyses with outcome measure ADLs, household activities, and miscellaneous activities, respectively. ADLs = activities of daily living; MAINtAIN = MAastrlcht Nurses Activity INventory; ICC = intra-class coefficient.

*Statistically significant association after Bonferroni-Holm correction.

within the team, referral to responsibility, and care routines. The fact that these rankings do not correspond implies that the barriers that are most often experienced among the nursing staff are not the barriers that are most strongly associated with the promotion of functional activity. For instance, although staffing level is the number one barrier according to the nursing staff, based upon the strength of the associations, it is ranked 21 st of the 33 barriers. The rankings based on the different kinds of regression (simple linear, unadjusted hierarchical linear, and adjusted hierarchical linear) to determine the relationship between the barriers and the extent to which functional activity was promoted, provided similar results; the top six barriers remained the same and, on average, other barriers mainly traded places (data not shown).

\section{Discussion}

This study showed that the barriers that are most often experienced among nursing staff are not necessarily the barriers that are most strongly associated with their promotion of functional activity among nursing home residents. 
Table 4. Comparison of the Barriers Based on Ranking.

Barriers ranked according to the height of the mean scores on the nine-point scales per item of the MAINtAIN-barriers
Barriers ranked according to the mean strength (mean $B$ ) of the associations ${ }^{a}$

\begin{tabular}{|c|c|c|c|}
\hline I. & Staffing level (O) & I. & Communication within team (S) \\
\hline 2. & Capabilities residents $(\mathrm{R})$ & 2. & Referral to responsibility $(\mathrm{S})$ \\
\hline 3. & Availability of resources $(O)$ & 3. & Care routines $(\mathrm{S})$ \\
\hline 4. & Conflict: time consuming $(\mathrm{P})$ & 4. & Social support of colleagues (S) \\
\hline 5. & Time (O) & 5. & Priority within organization $(\mathrm{O})$ \\
\hline 6. & Educational opportunities $(\mathrm{O})$ & 6. & Task perception: taking responsibility $(\mathrm{P})$ \\
\hline 7. & Organizational readiness $(\mathrm{O})$ & 7. & Sense of importance $(P)$ \\
\hline 8. & Expectations of colleagues $(\mathrm{S})$ & 8. & Support of manager (S) \\
\hline 9. & Residents' fear (R) & 9. & Presence of experts (O) \\
\hline 10. & Attitude residents $(\mathrm{R})$ & 10. & Expectations of colleagues $(S)$ \\
\hline II. & Priority within organization $(\mathrm{O})$ & II. & Availability of expertise $(P)$ \\
\hline 12. & Attention-seeking behavior ( $\mathrm{R})$ & 12. & Availability of resources $(O)$ \\
\hline 13. & Care routines $(\mathrm{S})$ & 13. & Educational opportunities (O) \\
\hline 14. & $\begin{array}{l}\text { Residents' and families' } \\
\text { expectations regarding care }(\mathrm{R})\end{array}$ & 14. & Prioritizing time over care $(\mathrm{P})$ \\
\hline 15. & Learned dependency $(R)$ & 15. & Time (O) \\
\hline 16. & Rules and regulations $(\mathrm{O})$ & 16. & Rules and regulations $(\mathrm{O})$ \\
\hline 17. & Communication within team (S) & 17. & Conflict: time consuming $(\mathrm{P})$ \\
\hline 18. & Self-efficacy (P) & 18. & Organizational readiness $(O)$ \\
\hline 19. & Relevance for residents (R) & 19. & Learned dependency $(\mathrm{R})$ \\
\hline 20. & Prioritizing time over care $(\mathrm{P})$ & 20. & Sense of difficulty $(P)$ \\
\hline 21. & Presence of experts $(\mathrm{O})$ & 21. & Staffing level $(\mathrm{O})$ \\
\hline 22. & Support of manager (S) & 22. & Visibility of results $(\mathrm{R})$ \\
\hline 23. & Social support of colleagues $(\mathrm{S})$ & 23. & Attitude residents $(\mathrm{R})$ \\
\hline 24. & Referral to responsibility (S) & 24. & Collaboration with experts $(S)$ \\
\hline 25. & Availability of expertise (P) & 25. & $\begin{array}{l}\text { Residents' and families' expectations } \\
\text { regarding care }(R)\end{array}$ \\
\hline 26. & Collaboration with experts (S) & 26. & Capabilities residents $(\mathrm{R})$ \\
\hline 27. & Visibility of results (R) & 27. & Risks for residents $(\mathrm{P})$ \\
\hline 28. & Sense of difficulty $(P)$ & 28. & Outcome expectations (P) \\
\hline 29. & $\begin{array}{l}\text { Task perception: taking } \\
\text { responsibility }(P)\end{array}$ & 29. & Relevance for residents $(\mathrm{R})$ \\
\hline 30. & Outcome expectations (P) & 30. & Self-efficacy (P) \\
\hline 31. & $\begin{array}{l}\text { Task perception: task of } \\
\text { physiotherapist }(\mathrm{P})\end{array}$ & 31. & $\begin{array}{l}\text { Task perception: task of } \\
\text { physiotherapist }(\mathrm{P})\end{array}$ \\
\hline 32. & Risks for residents $(\mathrm{P})$ & 32. & Residents' fear (R) \\
\hline 33. & Sense of importance $(P)$ & 33. & Attention-seeking behavior $(\mathrm{R})$ \\
\hline
\end{tabular}

Note. Barriers related to the residents $(R)$, the professionals $(P)$, the social context $(S)$, and the organizational and economic context (O). MAINtAIN = MAastrlcht Nurses Activity INventory; ADLs = activities of daily living.

aRanking based on the mean strength of the associations between a barrier and the ADLs, household activities, and miscellaneous activities subscales (i.e., the mean of the three Bs for each barrier of the adjusted hierarchical linear regression analyses; see Table 3). 
Barriers toward promoting functional activity are experienced on all levels, that is, the level of residents, the professionals, the social context, and the organizational and economic context. The most prevalent experienced barriers are on the organizational and economic level, for example, staffing levels and the availability of resources. The barriers related to the social context are generally most strongly associated with the perceived promotion of functional activity by nursing staff, particularly (a lack of) communication within the team and (a lack of) referral to responsibilities.

The findings of this study correspond with a review by Benjamin, Edwards, Ploeg, and Legault (2014) who found that the organizational barriers funding and staffing constraints were among the most mentioned barriers across studies (Benjamin et al., 2014), while fear (of falling) and health-related problems (i.e., "capabilities of residents" in our study) were the most mentioned barriers at resident level. Barriers related to the professionals, for example, the perceived difficulty of promoting functional activity, seem to be less important according to nursing staff. In contrast, studies on evidence-based practice or research utilization often find factors related to the professionals to be major barriers, for instance, a lack of knowledge or skills (Bostrom, Kajermo, Nordstrom, \& Wallin, 2008; Sitzia, 2001; Solomons \& Spross, 2011). These differences between barriers on different topics reaffirm that barriers are problem specific (Bostrom, Slaughter, Chojecki, \& Estabrooks, 2012; Kajermo et al., 2010) and underline the importance of studies that systematically map problem-specific barriers.

Although many studies have mapped nursing staff-experienced barriers, to our knowledge, only a few studies have examined the association between barriers and nursing behavior (e.g., Bostrom et al., 2008; Ebben et al., 2015), of which none focused on the promotion of functional activity by nursing staff. In line with our study, Ebben et al. (2015) found that social factors, for a large part, explain nursing staff adherence to protocol. Although the associations found in the present study may not be very strong, together the barriers related to the social context might to a great extent determine nursing behavior. The rankings of the barriers based on our regression analyses showed that generally barriers related to the social context were present in the top of the ranking. Social context barriers may, therefore, be an important target for strategies aiming to improve the promotion of functional activity, that is, behavior change in nursing staff.

Based on our cross-sectional study, it is likely that the barriers that are important according to the nursing staff are not always the barriers that have the greatest influence on their actual behavior. Due to social desirability, it may be easier for nursing staff to report barriers that are outside of their control. Staffing level, for example, is a barrier that is reported in many studies 
(Abrahamson, Fox, \& Doebbeling, 2012; Benjamin et al., 2014; Jun et al., 2016; Strand \& Lindgren, 2010). Although nursing staff may intuitively believe that more nursing staff leads to better quality of care (Arling \& Mueller, 2014), research shows that this is not always true (Backhaus, Verbeek, van Rossum, Capezuti, \& Hamers, 2015; Spilsbury, Hewitt, Stirk, \& Bowman, 2011). This demonstrates that it is important not only to address the most prevalent barriers but also to consider which combination of barriers is likely to have the greatest influence on nursing behavior.

\section{Strengths and Limitations}

This study has several strengths. First, our data were obtained from a nationwide sample, the variety in nursing homes making it possible to provide an overview of the barriers that matter the most to nursing staff in nursing homes in the Netherlands. Second, in this study, a wide range of barriers was taken into account, which makes it likely that the most important barriers were measured. Consequently, this study provides valuable input for the development of strategies aiming to overcome barriers and improve nursing staff promotion of functional activity. Conversely, some limitations of this study have to be taken into account. First, the cross-sectional design limits the identification of causal relationships between the experienced barriers and nursing staff-perceived behaviors. Second, this study used self-reported questionnaires assessing nursing staff-perceived behavior. Readers should keep in mind that this does not necessarily reflect their actual behavior (Dorresteijn, Rixt Zijlstra, Van Haastregt, Vlaeyen, \& Kempen, 2013; Van de Mortel, 2008); respondents might have overestimated the extent to which they promote functional activity. Future studies could investigate this to determine whether other data collection methods, for example, observations, are of added value to nursing staff's self-reports on promoting functional activity. Third, although a reversed facilitator is not always the same as a barrier (Jun et al., 2016), we chose to reverse the answer options of the positive formulated items, so that a higher score always indicated a stronger experienced barrier. The use of a nine-point scale allowed us to treat the barriers and facilitators as a continuum. In addition, presenting all results as barriers increased the readability of this article. However, we do acknowledge the importance of facilitators and recommend focusing not only on decreasing barriers but also on strengthening facilitators.

\section{Implications}

The present study provides implications for research and practice. Future research could include resident perspectives and examine their perceptions of 
the barriers toward performing functional activities. Future research with longitudinal designs, using repeated measures, could examine whether changes in nursing staff-experienced barriers are associated with changes in nursing behavior. Furthermore, to reduce the barriers nursing staff experience, strategies are needed. Although strategies are available (Cochrane Effective Practice and Organisation of Care Group [EPOC], 2002; Powell et al., 2015), they are often not very specific or tailored to the nursing home setting. Therefore, further research toward the development, feasibility, and effectiveness of strategies for this setting is warranted.

In nursing practice and nursing education, raising awareness of barriers and their (negative) influence on nursing staff behavior may help to address the barriers. The present study showed that barriers are experienced on different levels and that those related to the social context were generally most strongly associated with promotion of functional activity. Studies in different health care settings (Gifford et al., 2013; Holleman, van Tol, Schoonhoven, Mintjes-de Groot, \& van Achterberg, 2014) indicate that the enablement of successful leadership is an example of a potential relevant strategy that could be used to change nursing behavior. By influencing their colleagues, providing feedback, and providing an example, a leader could positively influence the social environment in a ward, reduce barriers, and consequently change nursing behavior. For instance, in addition to rewarding nurses for having someone neat and clean and out of bed before breakfast, a nurse could also be rewarded for promoting a resident's functional activity during the ADLs regarding personal care in the morning, particularly if personal care is expressed as important to the resident. Selecting which (combination of) barriers need to be addressed should not solely be based on the strength of the associations between the barriers and nursing behavior. We recommend taking into account the extent to which barriers are experienced by the nursing staff, the probability that changing these barriers is possible, and the likelihood that changes will actually lead to a change in behavior among nursing staff.

\section{Conclusion}

This cross-sectional nationwide study in Dutch nursing homes showed that the barriers that are most often experienced among nursing staff are not the barriers that are most strongly associated with their promotion of functional activity. Nursing staff experience barriers on the level of the residents, the professionals, the social context, and the organizational and economic context. Their most prevalent experienced barriers are related to the organizational and economic context, for example, staffing levels and the availability of resources. However, the barriers that are most strongly associated with the 
promotion of functional activity act on the level of social context, in particular (a lack of) communication within the team and (a lack of) referral to responsibilities. Based on the results of our study, we recommend that future studies aiming to improve the extent to which nursing staff promote functional activity among nursing home residents address a combination of barriers, including barriers of social context, taking into account both the extent to which barriers are experienced by the nursing staff and the likelihood that a change will actually lead to a change in behavior among nursing staff.

\section{Acknowledgments}

The authors thank the nursing staff and nursing homes who participated in this study.

\section{Declaration of Conflicting Interests}

The author(s) declared no potential conflicts of interest with respect to the research, authorship, and/or publication of this article.

\section{Funding}

The author(s) disclosed receipt of the following financial support for the research, authorship, and/or publication of this article: This work was supported by ZonMw, The Netherlands Organization for Health Research and Development (Grant 520001003).

\section{References}

Abrahamson, K. A., Fox, R. L., \& Doebbeling, B. N. (2012). Original research: Facilitators and barriers to clinical practice guideline use among nurses. AJN: The American Journal of Nursing, 112(7), 26-35. doi:10.1016/j.jamda.2013.12.080

Arling, G., \& Mueller, C. (2014). Nurse staffing and quality: The unanswered question. Journal of the American Medical Directors Association, 15, 376-378. doi:10.1016/j.jamda.2014.02.008

Backhaus, R., Verbeek, H., van Rossum, E., Capezuti, E., \& Hamers, J. P. (2015). Future distinguishing competencies of baccalaureate-educated registered nurses in nursing homes. Geriatric Nursing, 36, 438-444. doi:10.1016/j.gerinurse.2015.06.012

Benjamin, K., Edwards, N., Ploeg, J., \& Legault, F. (2014). Barriers to physical activity and restorative care for residents in long-term care: A review of the literature. Journal of Aging and Physical Activity, 22, 154-165. doi:10.1123/japa.2012-0139

Blair, C. E. (1997). Effect of self-care ADLs on self-esteem of intact nursing home residents. Issues in Mental Health Nursing, 20, 559-570. doi:10.1080/ 016128499248367

Bostrom, A. M., Kajermo, K. N., Nordstrom, G., \& Wallin, L. (2008). Barriers to research utilization and research use among registered nurses working in the care 
of older people: Does the BARRIERS scale discriminate between research users and non-research users on perceptions of barriers? Implementation Science: IS, 3, Article 24. doi:10.1186/1748-5908-3-24

Bostrom, A. M., Slaughter, S. E., Chojecki, D., \& Estabrooks, C. A. (2012). What do we know about knowledge translation in the care of older adults? A scoping review. Journal of the American Medical Directors Association, 13, 210-219. doi:10.1016/j.jamda.2010.12.004

Brown, D., McWilliam, C., \& Ward-Griffin, C. (2006). Client-centred empowering partnering in nursing. Journal of Advanced Nursing, 53, 160-168.

Cochrane Effective Practice and Organisation of Care Group. (2002). Data Collection Checklist. Retrieved from http://epoc.cochrane.org/sites/epoc.cochrane.org/files/ uploads/datacollectionchecklist.pdf

Davies, S., Ellis, L., \& Laker, S. (2000). Promoting autonomy and independence for older people within nursing practice: An observational study. Journal of Clinical Nursing, 9, 127-136.

den Ouden, M., Bleijlevens, M. H., Meijers, J. M., Zwakhalen, S. M., Braun, S. M., Tan, F. E., \& Hamers, J. P. (2015). Daily (in)activities of nursing home residents in their wards: An observation study. Journal of the American Medical Directors Association, 16, 963-968. doi:10.1016/j.jamda.2015.05.016

den Ouden, M., Kuk, N. O., Zwakhalen, S. M. G., Bleijlevens, M. H. C., Meijers, J. M. M., \& Hamers, J. P. H. (2016). The role of nursing staff in the activities of daily living of nursing home residents. Geriatric Nursing. Advance online publication. doi:10.1016/j.gerinurse.2016.11.002

Dorresteijn, T. A., Rixt Zijlstra, G. A., Van Haastregt, J. C., Vlaeyen, J. W., \& Kempen, G. I. (2013). Feasibility of a nurse-led in-home cognitive behavioral program to manage concerns about falls in frail older people: A process evaluation. Research in Nursing and Health, 36, 257-270. doi:10.1002/nur.21534

Ebben, R. H., Vloet, L. C., van Grunsven, P. M., Breeman, W., Goosselink, B., Lichtveld, R. A., . . . van Achterberg, T. (2015). Factors influencing ambulance nurses' adherence to a national protocol ambulance care: An implementation study in the Netherlands. European Journal of Emergency Medicine, 22, 199-205. doi:10.1097/ MEJ.0000000000000133

Edvardsson, D., Petersson, L., Sjogren, K., Lindkvist, M., \& Sandman, P. O. (2014). Everyday activities for people with dementia in residential aged care: Associations with person-centredness and quality of life. International Journal of Older People Nursing, 9, 269-276. doi:10.1111/opn.12030

Galik, E. M., Resnick, B., \& Pretzer-Aboff, I. (2009). "Knowing what makes them tick": Motivating cognitively impaired older adults to participate in restorative care. International Journal of Nursing Practice, 15, 48-55. doi:10.1111/j.1440172X.2008.01721.x

Gifford, W. A., Davies, B. L., Graham, I. D., Tourangeau, A., Woodend, A. K., \& Lefebre, N. (2013). Developing leadership capacity for guideline use: A pilot cluster randomized control trial. Worldviews on Evidence-Based Nursing, 10, 5165. doi:10.1111/j.1741-6787.2012.00254.x 
Grol, R. P., \& Wensing, M. (2004). What drives change? Barriers to and incentives for achieving evidence-based practice. Medical Journal of Australia, 180(6, Suppl.), S57-S60.

Harper Ice, G. (2002). Daily life in a nursing home: Has it changed in 25 years? Journal of Aging Studies, 16, 345-359.

Holleman, G., van Tol, M., Schoonhoven, L., Mintjes-de Groot, J., \& van Achterberg, T. (2014). Empowering nurses to handle the guideline implementation process: Identification of implementation competencies. Journal of Nursing Care Quality, 29(3), E1-E6. doi:10.1097/NCQ.0000000000000052

Jun, J., Kovner, C. T., \& Stimpfel, A. W. (2016). Barriers and facilitators of nurses' use of clinical practice guidelines: An integrative review. International Journal of Nursing Studies, 60, 54-68. doi:10.1016/j.ijnurstu.2016.03.006

Kajermo, K. N., Bostrom, A. M., Thompson, D. S., Hutchinson, A. M., Estabrooks, C. A., \& Wallin, L. (2010). The BARRIERS scale-The barriers to research utilization scale: A systematic review. Implementation Science: IS, 5, Article 32. doi:10.1186/1748-5908-5-32

Kuk, N. O., Bours, G., Zijlstra, G., Hamers, J. P., \& Kempen, G. I. (2015). Nurses' behaviors and perceived barriers to optimize function among nursing home residents [Special issue: Paper presented at the Gerontological Society of America, 68th Annual Scientific Meeting, Orlando, FL, USA]. Gerontologist, 55(Suppl. 2), 702 .

Kuk, N. O., Zijlstra, G. A. R., Bours, G. J. J. W., Hamers, J. P. H., \& Kempen, G. I. J. M. (2016). Development and usability of the MAINtAIN, an inventory assessing nursing staff behavior to optimize and maintain functional activity among nursing home residents: A mixed-methods approach. BMC Health Services Research, 16(1), Article 38. doi:10.1186/s12913-016-1288-7

MacRae, P. G., Schnelle, J. F., Simmons, S. F., \& Ouslander, J. G. (1996). Physical activity levels of ambulatory nursing home residents. Journal of Aging and Physical Activity, 4, 264-278.

Peri, K., Kerse, N., Robinson, E., Parsons, M., Parsons, J., \& Latham, N. (2008). Does functionally based activity make a difference to health status and mobility? A randomised controlled trial in residential care facilities (The Promoting Independent Living Study; PILS). Age and Ageing, 37, 57-63. doi:10.1093/ageing/afm 135

Powell, B. J., Waltz, T. J., Chinman, M. J., Damschroder, L. J., Smith, J. L., Matthieu, M. M., . . . Kirchner, J. E. (2015). A refined compilation of implementation strategies: Results from the Expert Recommendations for Implementing Change (ERIC) project. Implementation Science: IS, 10, Article 21. doi:10.1186/s13012015-0209-1

Resnick, B., Galik, E., \& Boltz, M. (2013). Function focused care approaches: Literature review of progress and future possibilities. Journal of the American Medical Directors Association, 14, 313-318. doi:10.1016/j.jamda.2012.10.019

Resnick, B., Gruber-Baldini, A. L., Zimmerman, S., Galik, E., Pretzer-Aboff, I., Russ, K., \& Hebel, J. R. (2009). Nursing home resident outcomes from the 
res-care intervention. Journal of the American Geriatrics Society, 57, 1156-1165. doi:10.1111/j.1532-5415.2009.02327.x

Resnick, B., Petzer-Aboff, I., Galik, E., Russ, K., Cayo, J., Simpson, M., \& Zimmerman, S. (2008). Barriers and benefits to implementing a restorative care intervention in nursing homes. Journal of the American Medical Directors Association, 9, 102-108. doi:10.1016/j.jamda.2007.08.011

Resnick, B., Simpson, M., Galik, E., Bercovitz, A., Gruber-Baldini, A. L., Zimmerman, S., \& Magaziner, J. (2006). Making a difference: Nursing assistants' perspectives of restorative care nursing. Rehabilitation Nursing, 31, 78-86. doi:10.1002/j.2048-7940.2006.tb00131.x

Sabol, V. K., Resnick, B., Galik, E., Gruber-Baldini, A. L., Morton, P. G., \& Hicks, G. E. (2011). Exploring the factors that influence functional performance among nursing home residents. Journal of Aging and Health, 23, 112-134. doi: $10.1177 / 0898264310383157$

Schols, J. M. G. A., Crebolder, H. F. J. M., \& van Weel, C. (2004). Nursing home and nursing home physician: The Dutch experience. Journal of the American Medical Directors Association, 5, 207-212. doi:10.1016/S1525-8610(04)70116-4

Sitzia, J. (2001). Barriers to research utilization: The clinical setting and nurses themselves. European Journal of Oncology Nursing, 5, 154-164. doi:10.1054/ ejon.2000.0115

Slaughter, S. E., Wagg, A. S., Jones, C. A., Schopflocher, D., Ickert, C., Bampton, E., . . Estabrooks, C. A. (2015). Mobility of Vulnerable Elders Study: Effect of the sit-to-stand activity on mobility, function, and quality of life. Journal of the American Medical Directors Association, 16, 138-143. doi:10.1016/j. jamda.2014.07.020

Solomons, N. M., \& Spross, J. A. (2011). Evidence-based practice barriers and facilitators from a continuous quality improvement perspective: An integrative review. Journal of Nursing Management, 19, 109-120. doi:10.1111/j.13652834.2010.01144.x

Spilsbury, K., Hewitt, C., Stirk, L., \& Bowman, C. (2011). The relationship between nurse staffing and quality of care in nursing homes: A systematic review. International Journal of Nursing Studies, 48, 732-750. doi:10.1016/j. ijnurstu.2011.02.014

Strand, T., \& Lindgren, M. (2010). Knowledge, attitudes and barriers towards prevention of pressure ulcers in intensive care units: A descriptive cross-sectional study. Intensive and Critical Care Nursing, 26, 335-342. doi:10.1016/j.iccn.2010.08.006

Van de Mortel, T. F. (2008). Faking it: Social desirability response bias in self-report research. Australian Journal of Advanced Nursing, 25(4), 40-48. 